OPEN ACCES

\title{
Role of Silver Nanoparticle Against Plant Pathogens
}

\author{
EK.Elumalai ${ }^{1, *}$, P.Vinothkumar ${ }^{2}$ \\ ${ }^{1}$ P.G. and Research Department of Zoology, Voorhees College, Vellore, 632001, Tamilnadu, India. \\ ${ }^{2}$ P G. and Research Department of Microbiology, Mohamed Sathak college of Arts and Science College, Chennai, Tamilnadu, India. \\ * Corresponding author: polarmail123@gmail.com Tel/fax.: +91-9840017657
}

\begin{abstract}
Biogenic synthesis of inorganic nanoparticles has been emerging as an important branch of nanobiotechnology. Biogenic silver nanoparticles (AgNPs) are proved to be potential antimicrobial agents against an array of pathogens. Aqueous extract of shade dried leaves of Conyza ambigua was used for the synthesis of AgNPs. The UV-VIS absorption spectroscopy, SEM, XRD were carried out to assess the formation AgNPs. SEM image divulges that AgNPs are quite polydispersed, the size ranging from $56 \mathrm{~nm}$. The above AgNPs were effective against A.niger, A.flavus and Sclerotium rolfsii. This study move towards biogenic synthesis of AgNPs using dried biomass appears to be cost effective, eco-friendly to that of conventional methods of nanoparticles synthesis.
\end{abstract}

Keywords: Conyza ambigua, Silver nanoparticles, SEM, XRD, A. niger, A. flavus, Sclerotium rolfsii.

Citation: EK.Elumalai and P.Vinothkumar. Role of Silver Nanoparticle Against Plant Pathogens. Nano Biomed. Eng. 2013, 5(2), 90-93. DOI: $10.5101 /$ nbe.v5i2.p90-93.

\section{Introduction}

Silver nanoparticles (AgNPs) have attracted intensive research interest because of their important applications as antimicrobial, catalytic, and surface-enhanced Raman scattering effect [1]. Silver has been used as an antimicrobial agent for centuries, the recent resurgence in interest for this element particularly focuses on the increasing threat of antibiotic resistance, caused by the abuse of antibiotics [2]. It is generally recognized that AgNPs may attach to the cell wall, thus disturbing cell-wall permeability and cellular respiration. The nanoparticles may also penetrate inside the cell causing damage by interacting with phosphorus- and sulfurcontaining compounds such as DNA and protein. Another possible contribution to the bactericidal properties of AgNPs is the release of $\mathrm{Ag}^{+}$from particles [2]. Although its specific antimicrobial mechanisms are still not completely understood.

The use of nano-sized AgNPs as antimicrobial agents has become more common as technological advances make their production more economical. One of the potential applications in which silver can be utilized is in management of plant diseases. Since silver displays multiple modes of inhibitory action to microorganisms, it may be used for controlling various plant pathogens in a relatively safer way compared to synthetic fungicides.
Until now limited research provided some evidence of the applicability of silver for controlling plant diseases [3]. Primary requirements for the potential use of silver in plant disease control include more information about antifungal activity of various silver compounds to plant pathogens and the development of better application strategies to increase the efficacy of disease suppression.

In recent years, plant-mediated biological synthesis of nanoparticles is gaining importance due to its simplicity and eco-friendliness. In this study the antiphytopathogenic activity of AgNPs synthesized using the leaves of Conyza ambigua (Asteraceae) were assessed.

\section{Material and methods}

\subsection{Plant material and synthesis of AgNPs}

Conyza ambigua leaves were collected from Villupuram District, India. The leaves were air dried for 10 days then were kept in the hot air oven at $60^{\circ} \mathrm{C}$ for 24 to $48 \mathrm{~h}$. The leaves were ground to a fine powder. $1 \mathrm{mM}$ silver nitrate was added to plant extract to make up a final solution $200 \mathrm{ml}$ and centrifuged at $18.000 \mathrm{rpm}$ for $25 \mathrm{~min}$. The collected pellets were stored at $-4^{\circ} \mathrm{C}$. The supernatant was heated at $50^{\circ} \mathrm{C}$ to $95^{\circ} \mathrm{C}$. A change in the color of solution was observed during the heating process. 


\subsection{Fungal strains}

The three test fungal species, A. niger, A. flavus and Sclerotium rolfsii were obtained from infected plants. These fungi are among the most important pathogenic fungi of economical significance to plants. Fungal strains were maintained on potato dextrose (PDA) agar. Fungal cultures were subcultured ( $1 \%$ inoculums) in PD broth at $35^{\circ} \mathrm{C}$ for at least two to four days before being used in the screening assays.

\subsection{UV-Vis spectra analysis}

The reduction of pure $\mathrm{Ag}^{+}$was monitored by measuring the UV-Vis spectrum of the reaction medium at $10 \mathrm{~min}$ after diluting a small aliquot of the sample into distilled water. UV-Vis spectral analysis was done by using UVVIS spectrophotometer UV-2450 (Shimadzu).

\subsection{Scanning electron microscopic (SEM) analysis}

SEM analysis was done using Hitachi S-4500 SEM machine. Thin films of the sample were prepared on a carbon coated copper grid by just dropping a very small amount of the sample on the grid, extra solution was removed using a blotting paper and then the film on the SEM grid were allowed to dry by putting it under a mercury lamp for $5 \mathrm{~min}$.

\subsection{X-Ray diffraction (XRD) analysis}

The AgNPs solution was further processed by repeated centrifugation at $5000 \mathrm{rpm}$ for $20 \mathrm{~min}$ followed by redispersion of the pellet of AgNPs into $10 \mathrm{ml}$ of deionized water. After freeze drying of the purified AgNPs, the structure and composition were analyzed by XRD. The dried mixture of AgNPs was collected for the determination of the formation of AgNPs by an X'Pert Pro x-ray diffractometer operated at a voltage of $40 \mathrm{kV}$ and a current of $30 \mathrm{~mA}$ with $\mathrm{Cu} \mathrm{K} \alpha$ radiation in a $\theta-2 \theta$ configuration. The crystallite domain size was calculated from the width of the XRD peaks, assuming that they are free from non-uniform strains, using the Scherrer formula (1).

$$
\mathrm{D}=0.94 \lambda / \beta \operatorname{Cos} \theta
$$

where $\mathrm{D}$ is the average crystallite domain size perpendicular to the reflecting planes, $\lambda$ is the $\mathrm{X}$-ray

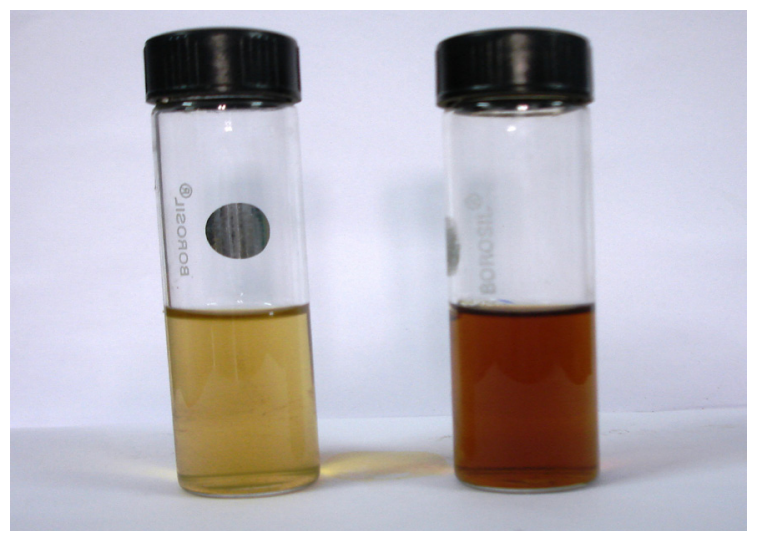

Fig. 1 Colour change of leaf extract containing silver before and after synthesis of AgNPs wavelength, $\beta$ is the full width at half maximum (FWHM), and $\theta$ is the diffraction angle. To eliminate additional instrumental broadening the FWHM was corrected, using the FWHM from a large grained Si sample (2).

$$
\beta \text { corrected }=(\text { FWHM2sample- } \text { FWHM2si }) 1 / 2
$$

This modified formula is valid only when the crystallite size is smaller than $100 \mathrm{~nm}$ [4].

\subsection{Antifungal activity study}

Antifungal activity of the synthesized AgNPs was determined using the agar well diffusion assay method [5]. Approximately $20 \mathrm{ml}$ of molten and cooled media (PDA) was poured in sterilized petri dishes. The plates were left overnight at room temperature to check for any contamination to appear. The fungal test organisms were grown in potato dextrose broth for $24 \mathrm{~h}$. A $100 \mathrm{ml}$ potato dextrose broth culture of each fungal organism $\left(1 \times 10^{5}\right.$ $\mathrm{cfu} / \mathrm{ml}$ ) was used to prepare fungal lawns. Agar wells of 5 $\mathrm{mm}$ diameter were prepared with the help of a sterilized stainless steel cork borer. Three wells were prepared in the agar plates. The wells were labeled as A, B, C. 'A' well was loaded with $10 \mu \mathrm{g}$ of AgNPs suspended 'hydrosol', ' $\mathrm{B}$ ' well was loaded with $10 \mu \mathrm{g}$ of plant extract and ' $\mathrm{C}$ ' well loaded with $10 \mathrm{mg}$ of positive control drugs. Ketoconazole as potential fungicides (Table 1) were used as positive controls. The plates containing the fungal and AgNPs were incubated at $37^{\circ} \mathrm{C}$ for $48-72 \mathrm{~h}$. The plates were examined for evidence of zones of inhibition, which appear as a clear area around the wells [6]. The diameter of such zones of inhibition was measured using a meter ruler and the mean value for each organism was recorded and expressed in millimeter.

\section{Result and Discussion}

It is well known that AgNPs exhibit yellowish brown color in aqueous solution due to excitation of surface plasmon vibrations in AgNPs [7]. The result obtained in this investigation is very interesting in terms of identification of potential weeds for synthesizing the AgNPs (Fig. 1). UV-Vis spectrograph of the colloidal solution of AgNPs has been recorded as a function of time. Absorption spectra of AgNPs formed in the reaction media at $10 \mathrm{~min}$ has absorbance peak at 440

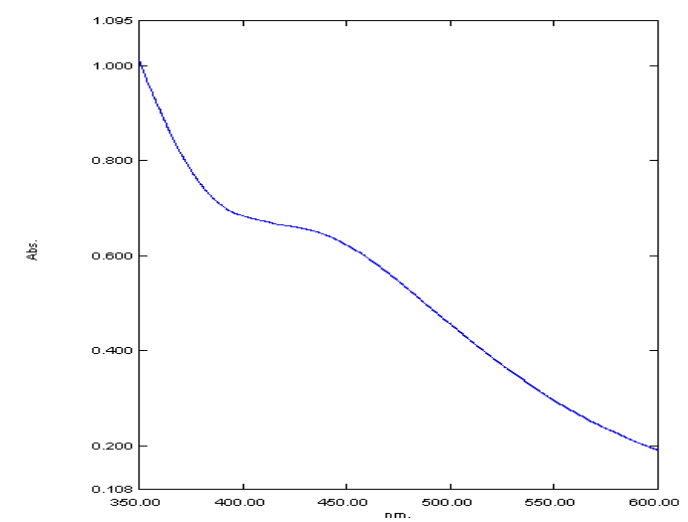

Fig. 2 UV-Vis absorption spectra of AgNPs synthesized from $C$. ambigua leaves at $1 \mathrm{mM}$ silver nitrate. 
http://nanobe.org

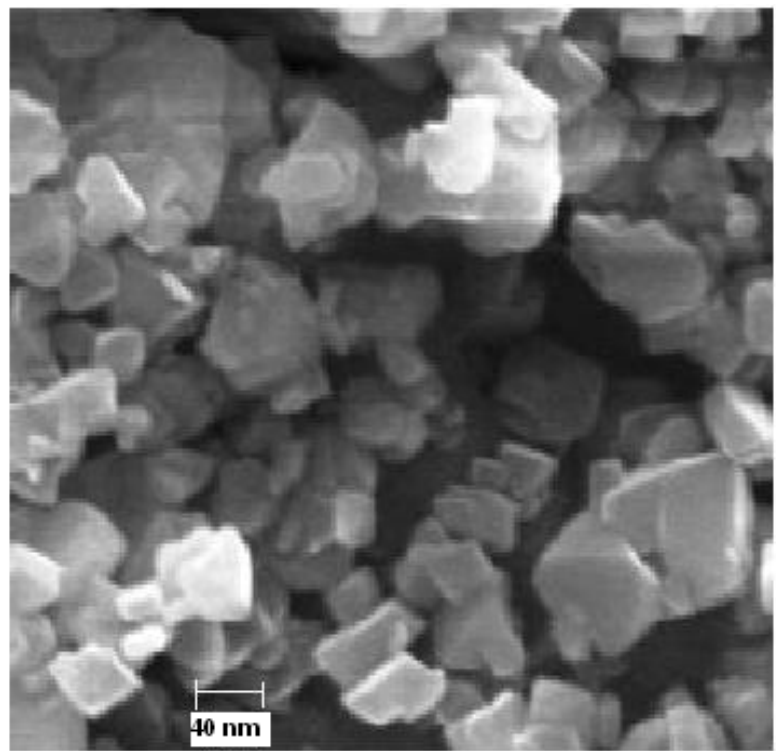

Fig. 3 SEM image of AgNPs formed by C. ambigua

$\mathrm{nm}$, broadening of peak indicated that the particles are polydispersed (Fig. 2). The SEM image showed relatively rectangle shape nanoparticle formed with diameter range 40-50 nm (Fig. 3). Similar phenomenon was reported by Chandran et al [8].

Further studies using X-ray diffraction were carried out to confirm the crystalline nature of the particles, and the XRD pattern obtained in Fig. 4 shows number of Braggs reflections that may be indexed on the basis of the face centered cubic structure of silver. There are four intense peaks in the whole spectrum of $2 \theta$ values ranging from 24 to 90 . A comparison of our XRD spectrum with the standard confirmed that the AgNPs formed in our experiments were in the form of nanocrystals, as evidenced by the peaks at $2 \theta$ values of $31.14^{\circ}, 46.16^{\circ}, 56.13^{\circ}$ and $71.56^{\circ}$, corresponding to (111), (200), (220) and (311), respectively for silver. These results clearly show that the AgNPs formed by the reduction of $\mathrm{Ag}^{+}$by the $C$. ambigua leaves extract were crystalline in nature [9]. As mentioned in the method section, the AgNPs once formed were repeatedly centrifuged and redispersed in sterile distilled water prior

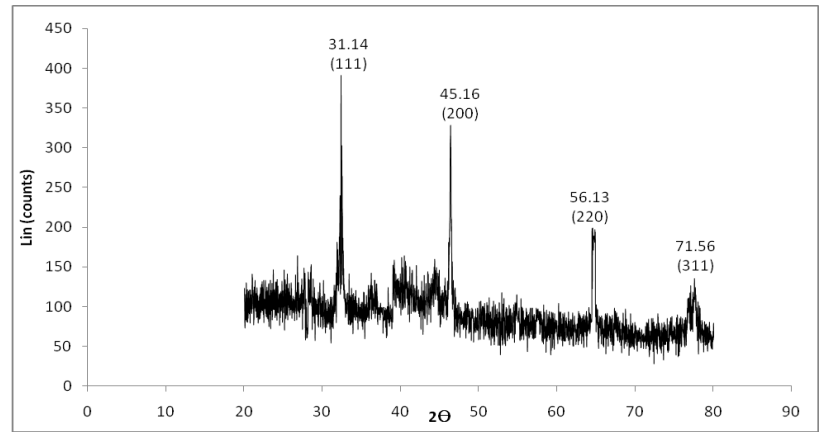

Fig. 4 XRD patterns of capped AgNPs synthesized using C. ambigua leaf extract

to XRD analysis, thus ruling out the presence of any free compound/protein that might independently crystallize and give rise to Bragg reflections.

Further the nanoparticle synthesis by green route was found highly toxic against three phytopathogenc fungal species at a concentration of $10 \mu \mathrm{g} \mathrm{AgNPs}$ revealed higher antifungal activity against $A$. niger, A. flavus whereas intermediated activity showed against Sclero-tium rolfsii. Plant extract showed minimum antifungal activity against fungal sps, it might be plant extract containing active phytochemicals like terpinoids, alkaloids, tannins and amino acids. According to Jo et al. [10], the mechanism of antifungal activity of AgNPs is based on the possibility that nanoparticles may attach to and penetrate the cell membrane and kill spores. The inhibitory activities of all the AgNPs reported in Table 1 are comparable with standard fungicides Ketoconazole (10 mg).

Table 1 The antifungal activity of AgNPs synthesis from C. ambigua.

\begin{tabular}{|l|l|l|l|}
\hline \multirow{2}{*}{ Plant pathogens } & \multicolumn{3}{|l|}{ Zone of inhibition in mm* } \\
\cline { 2 - 4 } & AgNPs & PE & Reference drug \\
\hline A. niger & 15 & 09 & 17 \\
\hline A. flavus & 13 & 08 & 18 \\
\hline Sclerotium rolfsii & 11 & 07 & 18 \\
\hline
\end{tabular}

* PE:Plant Extract, Reference drug: fungicide(Ketoconazole).
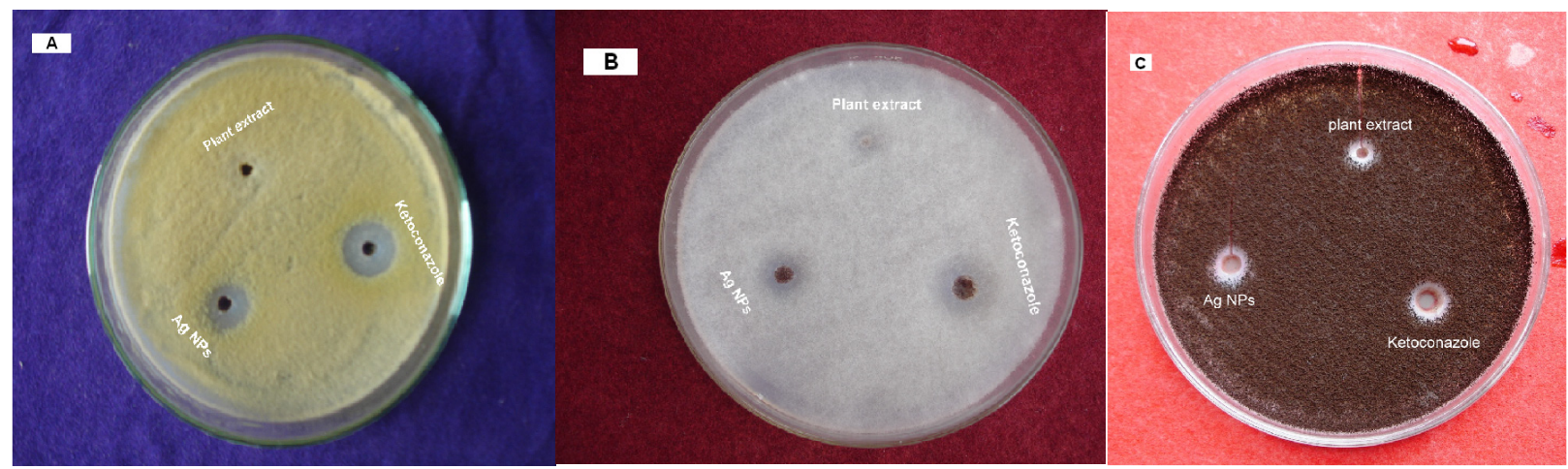

Fig.5 Antifungal activity of AgNPs against plant fungal pathogens A) A. flavus B) Sclerotium rolfsii C) A. niger 


\section{Conclusion}

The AgNPs were green synthesized using leaf extract of C. ambigua. Further, the above AgNPs revealed to possess an effective antifungal property against $A$. niger, A. flavus and Sclerotium rolfsii. The present study emphasizes the use of plant material for the synthesis of AgNPs with antiphytopathogens effect.

\section{Acknowledgements}

The authors are grateful to Department of Collegiate Education, Government of Tamilnadu, India for financial assistance.

\section{References}

1 Setua P., Chakraborty A., Seth D., Bhatta M.U., Satyam P.V. Synthesis, optical properties, and surface enhanced raman scattering of silver nanoparticles in non aqueous methanol reverse micelles. Sarkar, Phys. Chem. C.2007;111:3901.

2 Sambhy V., MacBride M.M., Peterson B.R., Sen A.J. Silver bromide nanoparticle/polymer composites: Dual action tunable antimicrobial materials. J. Am. Chem. Soc.2006; 128:9798.

3 Park H.J., Kim S.H., Kim H.J., Choi S.H. A new composition http://nanobe.org

of nanosized silica-silver for control of various plant diseases. Plant Pathol. j. 2006; 22:295-302.

4 Boulch .F, Schouler M.C., Donnadieu P., Chaix J.M., Djurado E. Domain size distribution of Y-TZP nanoparticles using XRD and HRTEM. Image Anal Stereol. 2001;20:157-161.

5 Perez C., Paul M., Bazerque P. Antibiotic assay by agar well diffusion method. Acta Biol. Med. Exp.1990;15:113.

6 Cheesbrough M. District laboratory practice in tropical countries. Low price edition. The press syndicate of the University of Cambridge, Trumpington Street Cambridge part,2000;2:157.

7 Krishnaraj C., Jagan E.G., Rajasekar S., Selvakumar .P, Kalaichelvan P.T., Mohan N, Colloid. Surface. B 2010; 76: 50-56.

8 Huang J., Li Q., Sun D., Lu Y., Su Y., Yang X., Wang H., Wang Y., Shao W., Hong N.J., Chen C. Biosynthesis of silver and gold nanoparticles by Novel sundried cinnamomum camphora leaf. Nanotechnology.2007;18:105104-105115.

9 Chandran S.P., Chaudhary M., Pasricha R., Ahmad A., Sastry M. Biotechnol Prog. 2006;22:577.

10 Jo Y., Kim B.H., Jung G. Antifungal activity of silver ions and nanoparticles on phytopathogenic fungi. Plant Dis.2009; 93:1037-1043.

Copyright:(c) 2013 EK.Elumalai and P.Vinothkumar. This is an open-access article distributed under the terms of the Creative Commons Attribution License, which permits unrestricted use, distribution, and reproduction in any medium, provided the original author and source are credited. 